\title{
Remote Sensing Techniques in Olive-Growing: A Review
}

\author{
G Nolè*, A Pilogallo, A Lanorte and F De Santis
}

Department of Economics and Management, Italy

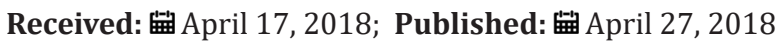

*Corresponding author: G Nolè, Department of Economics and Management, Italy

\begin{abstract}
The evolution of remote sensing techniques, the rising availability of increasingly accurate and reliable technologies and the widening provision of precise and detailed data constitute the framework within which more and more specific sectors use remote sensing. Agriculture is one of the sectors where different applications of remote sensing can prove their effectiveness as they offer the possibility of gaining new perspectives, detecting phenomena not visible from the ground and in replacing man when inspecting territories dangerous, contaminated or difficult to access is necessary. Present paper aims to illustrate remote sensing techniques currently available in olive growing, highlighting their advantages in terms of optimisation of production processes and natural resources exploitation, environmental footprint, traceability of final products and monitoring of yield.
\end{abstract}

Keywords: Olive growing; Remote sensing; Satellite data; Unmanned aerial vehicle (UAV)

\section{Introduction}

Remote sensing is a set of techniques that allows the exploitation of different way in which natural surfaces interact with electromagnetic energy from a source to obtain information about their characteristics. Until a few years ago, data and images could be acquired just by aircraft equipped with special cameras whose use had to be designed in detail with considerable expenses and difficult replicability of acquisition. In recent years, data acquired by satellites have become available and later continuous technological evolution has made it possible to perform the same service at even higher resolution through unmanned aerial vehicle (UAV), allowing considerable cost savings and, most importantly, making this technology no longer an exclusive prerogative of scientific community. At present the choice of instrument depends essentially on the costs and on the level of detail desired. Using UAV, increasingly common and executable with different resolutions, still has a price justified only by large-scale projects; satellite data have a spatial resolution ranging from $10 \mathrm{~m}$ to 30 centimetres, suffer from interference such as the presence of the atmosphere and cloud cover but, at lower resolutions, are available free of charge. At present, the satellite constellations from which data and images can be drawn are different. Optical satellite images may have spatial resolutions (i.e., pixel size) of kilometres or even centimetres. In the case of free data, the spatial resolution is 20 to 30 meters on the ground and the most common are Landsat, Aster and Sentinel 2 and 3. Multispectral sensors such as Landsat, Spot, Quickbird, Aster, etc., have low spectral resolutions and therefore have bands of considerable amplitude; this does not allow good discrimination of spectral characteristics.

Instead, hyperspectral sensors (Mivis, Aviris, HyMap, etc.) have a better spectral resolution and allow to obtain a satisfactory discrimination of some absorption bands. In contrast, hyperspectral sensors do not have a wide coverage of the Earth's surface and this is one of the reasons why multispectral sensors are preferred for different territorial applications. Remote sensing data with a high spatial resolution allow a considerable increase in investigation scale, with performances in terms of accuracy, comparable to those obtained with traditional aerial photogrammetric techniques. Increasing spatial resolution makes the detail of the object's shape grow, but implies an increment of the parameters needed to describe classes (Figure 1). Normally, high spatial resolution with current satellite surveying technologies corresponds to a reduced spectral resolution, which prevents a detailed description of a surface based on energy measurements reflected. Moreover, satellite data with high or very high spatial resolution are hardly free of charge and for the case studies dealt with, which concern large scale areas, data with a wider spectral resolution (to the detriment of spatial 
resolution) were considered. Different data collection methods differ in terms of acquisition frequency, processing times and delivery timeliness. Although UAV acquisition can be programmed as desired while satellite images are acquired at regular intervals, the latters allow more complex elaborations based on the analysis of the available historical series. The utilization of UAV is not only limited to diagnostic context but also to practical applications: in Italy they have already been successfully tested in the biological treatment of maize against some kinds of lepidoptera; in Japan, instead, a large part of spraying with herbicides and fertilizers is carried out on rice paddies by means of small tanks implanted on drones which, depending on the parameters measured, dose their concentrations (Figure 2).

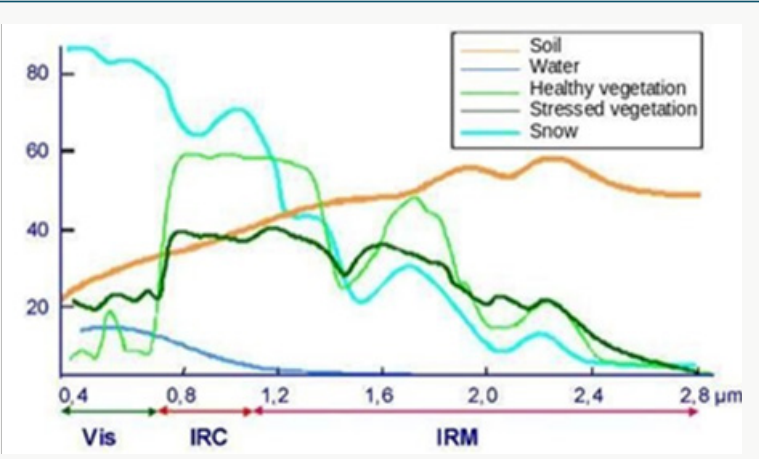

Figure 1: Spectral Signature.

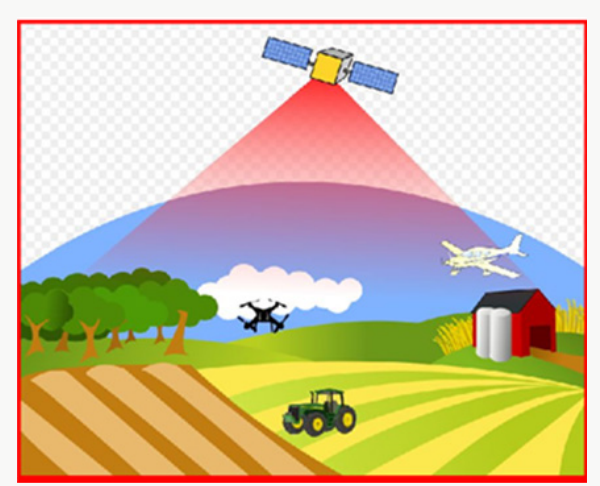

Figure 2: Remote Sensing.

The increasing availability of powerful tools to improve the efficiency of agronomic practices and the increasing sensitivity to the environmental footprint of the agricultural sector are having an important impact in different parts of the world.In the European context, for example, the Dutch government has budgeted up to $€ 1.4$ million for the purchase of satellite data to improve sustainability and efficiency of agriculture. These data will include detailed information on soil characteristics, atmosphere and crop development. Specialised farms will be able to analyse them to provide farmers with targeted advice on irrigation, fertilisation and pesticide spraying activities. Satellite data will be open and starting from next seasonon dedicated platform (http://satellietdataportaal. $\mathrm{nl}$ ), allowing everyone to have free access to the database. Dutch agricultural and horticultural sector enjoys a strong international reputation so the government wants to support this leading position by investing in innovation. Satellite data allow farmers to monitor crop progress very closely and take corrective action exactly where it is needed, resulting in greater efficiency and sustainability. Data purchased by the government will be analysed and processed by scientific institutes and specialised companies and then converted into information directly accessible to farmers, for example on the state of health of the vegetation (http://www.groenmonitor.nl) or on fertilisation and irrigation (http://www.akkerweb.nl). Smart methods and technologies will be able to generate significant savings for farmers in terms of fuel, seeds, artificial fertilisers, crop protection agents and water. Also FAO has recently developed software called Collect Earth that exploits the databases of Google Earth Engine, the portal thanks to which you can access millions of images taken by U.S. and European satellites, completely free and open source, in order to bring more and more users to satellite data to monitor territory, observe land and visualize their evolution.

Moreover it is not by chance that remote sensing techniques have significantly contributed to the creation of the Information System and the Territorial Database currently managed by AGEA, the Agency for Agricultural Disbursements, which since 1982 has started to acquire first aerial data for the establishment of the olive cultivation register (Reg. $\mathrm{n}^{\circ} 2276 / 79$ ). This impressive and structured data collection is today one of the most important sources of information not only on the agricultural and forestry sectors but also on the definition of the evolution of land use and consequently the identification of land degradation phenomena.

\section{Remote sensing and olive growing}

More than 11 million hectares of olives are grown in the world, spread across the five continents, two hemispheres and 47 countries [1]. At present, olive oil is consumed in over 160 countries registering a production amounting in more than 2500 thousands tonnes2. These numbers are an indication of how important olive sector is for the economy of the 47 producer countries, and how much an efficiency of the production cycle and a reduction in its environmental footprint can benefit the entire terrestrial ecosystem. The application of remote-sensing techniques in olive growing may to contribute significantly to the increase in olive grove productivity and to the contextual reduction of the environmental impact of farming practices. They allow more specific and differentiated intervention according to the variability within an olive grove, thus allowing advantages to be obtained in terms of:

a) Monitoring and optimization of fertilization and plant health protection operations on the basis of site-specific surveys.

b) The most appropriate choice of irrigation method and quantity of water to be supplied depending on specific water demand;

c) Evaluation of the morphological characteristics of the plants and planning of the most appropriate pruning operations; 
d) The estimation of olive productivity and subsequent oil yield.

Once the purely cultivation phase is over, monitoring activities carried out with the support of remote sensing can also be useful for the traceability of final products (table olives and/or olive oil) and the consequent possibility of guaranteeing and certifying origin, cultivation regime (biologic, sod seeding, minimum tillage, etc.) and other information useful to make the consumer's choice as aware as possible.

First high resolution applications have been made by integrating satellite images and probabilistic techniques for counting olive trees with the purpose to provide a support in surveying and inventorying forests and areas covered with other kinds of arboreal crops and, in particular for olive trees, in assessing estimates of the production of plantations [2]. With the same purpose of reducing considerably the effort of manual tree counting and providing a useful instrument for environmental applications of fruit orchard, plantation and open forest population monitoring, project called Arbor Crown Enumerator (ACE) was developed for tree crown detection from multispectral Very High-resolution (VHR) satellite imagery [3]. Using a combination of the Red band and Normalized Difference Vegetation Index (NDVI) thresholding, and the Laplacian of the Gaussian (LOG) blob detection method, this methodology is intended to replace the previous OLICOUNT software and to broaden its scope of application. OLICOUNT, a tool launched by the European Commission with the specific goal to estimate the number of olive trees in France, Italy, Spain, Portugal, and Greece, has automated this counting process to some extent and it has been an important reference in agricultural policies. It has been used, for example, to develop an olive tree registration in the framework of the database accession process to the European Union by the Turkish Government [4].

Reliable methods for the estimation of crown architecture is another key issue for the quantitative evaluation of tree crop adaptation to environment conditions as for an accurate 3D model of the tree crowns can provide information about critical aspects of plant growth and development and, therefore, about its suitability for some specific training systems. This is especially important in olive breeding programs aimed at developing new cultivars suitable either to discontinuous (open vase configuration) or continuous (hedgerow) canopy. Results from studies conducted acquiring data by means of consumer-grade cameras on board a UAV [5], show a high agreement between remote sensing estimation and field measurements of crown parameters. Torres [6] have carried out several tests to estimate exact volume of canopies through threedimensional processing of images acquired by drone on different kinds of olive grove (traditional and very high density). Results obtained, later compared with on the ground measurements, have highlighted some differences attributable to the in-field method of calculating volume. The equation conventionally used, in fact, considers trees as forms ellipsoidal, leading to inaccurate estimates due to excessive geometric simplification. This work, in addition to confirming the potential application of survey techniques by UAV, also provides an alternative methodology that can fill in application gaps belonging to traditional procedures.

Some remote sensing applications have been tested on large olive groves in order to determine the foliar area by indirect measurements and, on the basis of these, to evaluate presumed yield and to estimate exact volumes of plant protection products to be sprayed according to the foliar surface capable of intercepting the product itself (directly proportional to the foliar surface) and defining a correct pruning management strategy, in terms of intensity and rotation. A further interesting application by CNR and University of Florence's researchers intended to simulate the olive-growing productivity through the integration of remote sensing and in-field data [7]. Multi-step methodology combines olive NDVI values with meteorological data within a parametric model that allows the estimation of primary productivity daily gross weight (GPP). Further elaborations and the use of a specific biogeochemical model allow them to estimate olive yield expressed in terms of quintals per hectare. This value, relative to the years in which the simulation was carried out, was then compared with data collected in provincial statistics showing the quality of the method developed and reproducing with satisfactory accuracy the inter-annual variation in olive yield throughout the whole region. Current climate change suggests that in many European countries, as in other parts all over the world, lack of adequate rainfall may be one of the major factors limiting agricultural production in general. For this reason, some applications have been developed with the specific aim of monitoring the water stress of crops and optimizing the use of water resources. One of these studies was conducted in Chile [8] and led to the design of a real Geo-Informatics System for Irrigation Management aimed to increase water productivity $(\mathrm{kg} /$ m3) and to adapt agricultural systems to water scarcity. Water demand of olive trees as well as biomass production and, therefore, crop yield are directly related to the ability of plants to absorb and convert solar radiation.

In this framework, stand all the researches aimed at establishing two-way relations between the fraction of Intercepted Photo synthetically Active Radiation (fIPAR) and some kind of satellite index. Just for example, scientific studies carried out in Spain [9] investigated on the relationship between fIPAR and the Normalized Difference Vegetation Index (NDVI) using radiative transfer modelling methods and field measurements. In the field of disease detection some remote sensing-based efficient methods were developed for detecting eventual disease in early stages and for discriminating among severity levels in order to adequately calibrate the kind of intervention. Calderon [10], for example, assessed the potential of using vegetation indices for the early detection of the soil-borne fungus Verticillium wilt in olive orchards using indicators based on crown temperature (CWSI), visible ratios (B, BG, BR), and chlorophyll fluorescence estimates FLD3 to detect 
disease in earlier stages and structural multispectral indices such as Normalized Difference Vegetation Index (NDVI), PRI, chlorophyll and carotenoid indices for the detection of the presence of moderate to severe damage [11]. Ultimately it seems appropriate to present the case of an application conducted by the USDA Forest Service to detect and to evaluate the spread of Russian olive (Elaeagnus angustifolia L.) throughout the Fishlake National Forest [12]. This plant, a thorny shrub or tree, was intentionally introduced and planted for windbreaks, erosion control, wildlife habitat, and other horticultural purposes but during the 20th century, it escaped cultivation and spread notably invading riparian environments in semiarid regions of the western United States. Remote sensing has been used to map weed infestations from Russian olive trees and other invasive weeds and occurring in dense stands.

\section{Conclusion}

Ever more frequent evidences of climate change and growing environmental awareness impose a reflection on methodologies and techniques that can effectively contribute to make more efficient and less impactful the agricultural sector, which is one of the largest productive sectors in the world and, on the other hand, is responsible for a series of negative impacts on global ecosystem. For the whole agricultural compartment, this work specifically analyses the olive sector for which priorities have emerged from many parts of the world to make cultivation and production cycle more sustainable, reducing costs for farmers and ensuring greater transparency for consumers on the origin and agronomic and processing techniques. Remote sensing is one of the tools that best serves as a support in all the issues mentioned by proposing methodologies and elaborations adaptable to the most disparate purposes and replicable at any scale and in any territory. Listed applications are useful to give an idea of how wide is the repertoire of the results that can be obtained in order to compose a very detailed cognitive framework, to support farmers in the management of their olive groves or to support administrators and political decision makers in the choice of the most appropriate agricultural policies.

\section{References}

1. International Olive Council (2015) International Olive Oil Production costs study: results, conclusions and recommendations.
2. González J, Galindo C, Arevalo V, Ambrosio G (2007) Applying Image Analysis and Probabilistic Techniques for Counting Olive Trees in HighResolution Satellite Images. In Blanc Talon J, Philips W, Popescu D, Scheunders P (eds) Advanced Concepts for Intelligent Vision Systems. ACIVS 2007. Lecture Notes in Computer Science, 4678.

3. DaliakopoulosI N, Grillakis EG, Koutroulis AG, Tsanis IK (2009) Tree Crown Detection on Multispectral VHR Satellite Imagery. Photogrammetric Engineering \& Remote Sensing 75(10): 1201-1211.

4. Ceylan N, Unal E, Masson J (2009) A Case Study of Developing An Olive Tree Database For Turkey. Photogrammetric Engineering \& Remote Sensing 75(12): 1397-1405.

5. Díaz Varela RA, de la Rosa R, León L, Zarco Tejada PJ (2015) HighResolution Airborne UAV Imagery to Assess Olive Tree Crown Parameters Using 3D Photo Reconstruction: Application in Breeding Trials. Remote Sens 7(4): 4213-4232.

6. Torres Sánchez J, López Granados F, Serrano N, Arquero O, Peña JM (2015) High Throughput 3-D Monitoring of Agricultural-Tree Plantations with Unmanned Aerial Vehicle (UAV) Technology. PLoS ONE 10(6): e0130479.

7. Moriondo M, Chiesi M, Brilli L, Bindi M, Maselli F (2011) Simulation of olive productivity in Tuscany through the integration of remote sensing and data on the ground. Proceedings 1 at ASITA National ConferencePalace of Colorno, Italy.

8. Ortega Farías S, Ortega Salazar SC, Poblete Echeverría CT, Poblete TA, Kilic AR, et al. (2015) UAV with Thermal Imaging for High Resolution ET and Water Stress Monitoring in Olives and Vineyards in Chile. 2015 International Workshop on Evapotranspiration Mapping for Water Security. The World Bank, Washington, DC, USA.

9. Guillén Climent ML, Zarco Tejada PJ, Villalobos FJ (2012) Estimating radiation interception in an olive orchard using physical models and multispectral airborne imagery. Israel Journal of Plant Sciences 60:107121.

10. Calderón R, Navas Cortés J, Lucena C, Zarco Tejada P (2013) Highresolution airborne hyperspectral and thermal imagery for early detection of Verticillium wilt of olive using fluorescence, temperature and narrow-band spectral indices. Remote Sens Environ 139: 231-245.

11. Salamí E, Barrado C, Pastor E (2014) UAV Flight Experiments Applied to the Remote Sensing of Vegetated Areas. Review. Remote Sens 6(11): 11051-11081.

12. Hamilton R, Megown K, Lachowski H, Campbell R (2006) Mapping Russian olive: using remote sensing to map an invasive tree. RSAC0087-RPT1. Department of Agriculture Forest Service, Remote Sensing Application Center, Salt Lake City, USA.
CC (P) This work is licensed under Creative

To Submit Your Article Click Here: Submit Article

DOI: 10.32474/CIACR.2018.02.000138

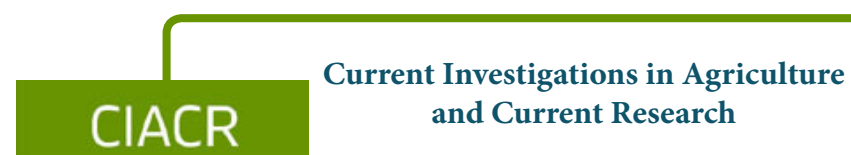

Assets of Publishing with us

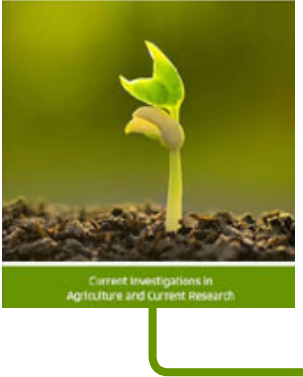

- Global archiving of articles

- Immediate, unrestricted online access

- Rigorous Peer Review Process

- Authors Retain Copyrights

- Unique DOI for all articles 